\title{
Study on Reservoir-caprock Assemblage by Dual Logging Parameter Method
}

\author{
Jingling $\mathrm{Xu}^{1,2, *}$, Luofu Liu ${ }^{3,4}$, Fei Xiao, ${ }^{3,4}$, Changchun $\mathrm{Zou}^{1,2}, \mathrm{Hao} \mathrm{Li}^{5}$, Yuanzheng Wang ${ }^{6}$ \\ and Ying Wang ${ }^{3,4}$
}

\begin{abstract}
${ }^{1}$ Key Laboratory of Geo-detection (China University of Geosciences, Beijing), Ministry of Education, Beijing 100083, China; ${ }^{2}$ State Key Laboratory of Geological Processes and Mineral Resources, China University of Geosciences, Beijing 100083, China; ${ }^{3}$ State Key Laboratory of Petroleum Resources and Prospecting, China University of Petroleum, Changping, Beijing 102249, China; ${ }^{4}$ Basin \& Reservoir Research Center, School of Geosciences, China University of Petroleum, Changping, Beijing 102249, China; ${ }^{5}$ SINOPEC Shengli oilfield, Shengli, Shandong 257001, China; ${ }^{6}$ Technology research institute of Onshore oil field in JiDong oilfield company, Tanghai, Hebei 063200, China.
\end{abstract}

\begin{abstract}
Generally, logging curve shape and logging data are used to identify and evaluate the reservoir and caprock in the study of reservoir-caprock assemblage in conventional logging method, which fails to distinguish the reservoircaprock assemblage and allocation relation of different producing layers (high and low production gas layer, dry layer). In order to analyze and discriminate the types of reservoir-caprock assemblage and the corresponding productivity quickly and accurately, the dual logging parameter method is put forward to study reservoir-caprock assemblage and predict its productivity. Besides, discrimination standard and allocation relationship of reservoir-caprock assemblage determined by the dual parameters of reservoir porosity and caprock porosity are also established.
\end{abstract}

Keywords: Different producing layer, dual logging parameter, productivity, reservoir-caprock assemblage.

\section{INTRODUCTION}

Generally, reservoir and caprock are firstly evaluated in the study of reservoir-caprock assemblage, respectively, and then their allocation relations are studied [1-4].

High quality reservoir develops lots of reservoir spaces such as the fractures and solution pores, and a higher permeability, larger thickness and purer lithology compared with the non-reservoir [5]. Thus, the good reservoir is characterized with high porosity, permeability, gas saturation and gas abundance.

High quality caprock has good sealing ability. The total porosity of mudstone caprock reflects the compaction degree, that is a smaller porosity reflects a higher compaction degree, inferring smaller throat radius, higher capillary force, lower permeability and an overall better sealing ability [6-8]. Therefore, good caprock is featured with pure lithology, large thickness, low porosity, low permeability and low sand content.

In order to evaluate the reservoir-caprock assemblage intuitively and establish their correlation, the reservoir-caprock dual logging parameter (reservoir porosity and caprock porosity) method is put forward. The method is proposed based on the porosity of reservoir and caprock. By this method, the porosity of reservoir and caprock would be combined to establish charts which would be used to study the response

*Address correspondence to this author at the Key Laboratory of Geodetection (China University of Geosciences, Beijing), Ministry of Education, Beijing 100083, China; Tel: 0086-10-82321446;

Fax: 0086-10-82321044; E-mail: jlxu@cugb.edu.cn characteristics of different producing layers according to the characteristics of the dual porosity and some other relevant parameters. Finally, the criterion for this method to study reservoir-caprock assemblage of different gas production is built.

\section{PRINCIPLE OF RESERVOIR-CAPROCK DUAL PARAMETER METHOD}

\subsection{Identifying Different Producing Layers According to Logging Response}

High production gas layers, low production gas layers and dry layers can be identified according to well test combined with conventional and imaging logging.

(1) The reservoir-caprock assemblage of gas layer with high daily production up to more than $100,000 \mathrm{~m}^{3}$ is characterized with low and high superimposed nature gamma (GR) and resistivity values, an overall high interval transit time value (AC) superimposed with some spikeshaped extra high values [9-12].

(2) The reservoir-caprock assemblage of gas layer with low daily production less than $10,000 \mathrm{~m}^{3}$ is featured with low and high but similar values superimposed gamma value and fluctuated GR curve, impure lithology, an overall high interval transit time value and jugged or bulged AC curve, and high resistivity values.

(3) The reservoir-caprock assemblage of dry layer is characterized with low gamma values, a stable interval transit time value and high resistivity values. 
In a word, the more the difference of logging response of reservoir and caprock, the better the reservoir-caprock assemblage will be, and vice versa.

\subsection{Calculating Reservoir-caprock Parameters}

After recognizing the assemblages of different gas production rate, the top and bottom depth is recorded respectively and the respective thickness, porosity, permeability and sand content of reservoir and caprock are calculated. Porosity is the most significant parameter [13], and we only use porosity to illustrate characteristics of reservoir-caprock assemblage.

\subsection{Building the Criterion for Reservoir-caprock Dual Parameter Method to Study Reservoir-caprock Assem- blage}

The porosities of reservoir and caprock in different producing layers were combined to establish a chart aimed at studying the response characteristics of the dual parameter of different producing layers assemblages comparatively and analyzing the rule. Finally, the criterion for reservoir-caprock dual parameter method was established to study the reservoir-caprock assemblages of different producing layers.

\section{RESERVOIR-CAPROCK ASSEMBLAGE LOGGING RESPONSE CHARACTERISTICS BASED ON RESER- VOIR-CAPROCK DUAL PARAMETER METHOD}

\subsection{Reservoir-caprock Assemblage Logging Response Characteristics of High Production Gas Layer}

Taking the test section 3650-3700m of Well XC12 as an example, the conventional logs shows a large thickness of mudstone in the upper test section (Fig. 1). The blue gamma line in the first channel presents a low value with little fluctuated curve and the interval transit time curve in the second channel is of an overall low value. In the electric imaging log [14], it is easy to find sandstone of a large thickness, pure lithology, fine color and well developed low-angel fractures.

As the reservoir and caprock are distinguished, the calculated and counted parameters of reservoir and caprock are shown in Table 1. The porosity and permeability of the caprock of testing section are low while that of reservoir are large, contributing to high production reaching $42,000 \mathrm{~m}^{3} / \mathrm{d}$.

Table 1. Major reservoir and caprock parameters of high production layers, Well XC12.

\begin{tabular}{|c|c|c|}
\hline \multirow{2}{*}{ Parameter } & Caprock sample & Reservoir sample \\
\cline { 2 - 3 } & $\mathbf{1}$ & $\mathbf{1}$ \\
\hline \hline Top depth (m) & 3672.3 & 3677 \\
\hline Bottom depth (m) & 3677 & 3694 \\
\hline Thickness (m) & 4.7 & 17 \\
\hline POR $(\%)$ & 0.047 & 8.626 \\
\hline PERM $(\mathrm{mD})$ & 0.023 & 2.653 \\
\hline
\end{tabular}

The chart is built combined with the porosity of reservoir and caprock and shown in the Fig. (1) on the right side. According to the chart of reservoir-caprock assemblage, the porosity of reservoir is larger than $5 \%$ and that of caprock is smaller than $3 \%$ in the high production gas layer, and their combination is scattered in the right-down part of correlation chart.

\subsection{Reservoir-caprock Assemblage Logging Response characteristics of Low Production Gas Layer}

Testing section of $3725-3761 \mathrm{~m}$ of Well XC12 is studied as a case of low production gas layer. In the conventional logs, it is easy to distinguish the mudstone caprock with thickness of $11 \mathrm{~m}$ in the upper testing section (Fig. 2). The section develops a low gamma value shown in the blue line in the first channel with an aiguilles corresponding to the black mudstone strips in the imaging picture, an interval transit time curve of low values and an obviously high resistivity value.

In the electric imaging log, an obvious dividing line is easily distinguished. The caprock presents a more intense color, impure lithology, low high porosity and a relatively low chroma threshold, while the reservoir shows a light color, worse chromaticity diagram with a smaller chroma threshold.

After distinguishing the reservoir and caprock, the parameters of reservoir and caprock are calculated and counted, and shown in the Table 2 . Comparing with the high production layers, the low production layer has larger caprock porosity and permeability, while these of reservoir are smaller.

A new chart is built based on the combination of the porosity of reservoir and caprock as shown in Fig. (2) on the right side, the low production gas layer reservoir-caprock assemblage can be recognized with the reservoir porosity between $3 \%$ and $5 \%$ and that of caprock smaller than $4.6 \%$. The assemblage distributes in the mid-down part of the correlation chart.

\subsection{Reservoir-caprock Assemblage Logging Response Characteristics of Dry Layer}

The section of $3640-3674 \mathrm{~m}$ of Well XC12 is studied as an typical example of dry layer, the blue GR curve in the first channel presents a low value obviously lower than 70 API, the thickness of the upper caprock is $6 \mathrm{~m}$ and the lower is $8.5 \mathrm{~m}$, the $\mathrm{AC}$ value of blue curve in the second channel decreases slightly in the dry layers, where the resistivity value increases significantly, which are all shown in the conventional logging curves (Fig. 3). The reservoir and caprock are pure lithology with fine color according to the electric imaging logging interpretation (Fig. 3).

As the reservoir and caprock are distinguished, the calculated and counted parameters are presented in the Table $\mathbf{3}$. The porosity of reservoir and caprock is small and the same to the reservoir permeability, inferring the lack of reservoir spaces despite the pure lithology. The layer is interpreted as dry layer by well logging and there is no industrial gas flow in the test. Combined with the porosity of reservoir and caprock, the chart is established and shown in the Fig. (3) to 

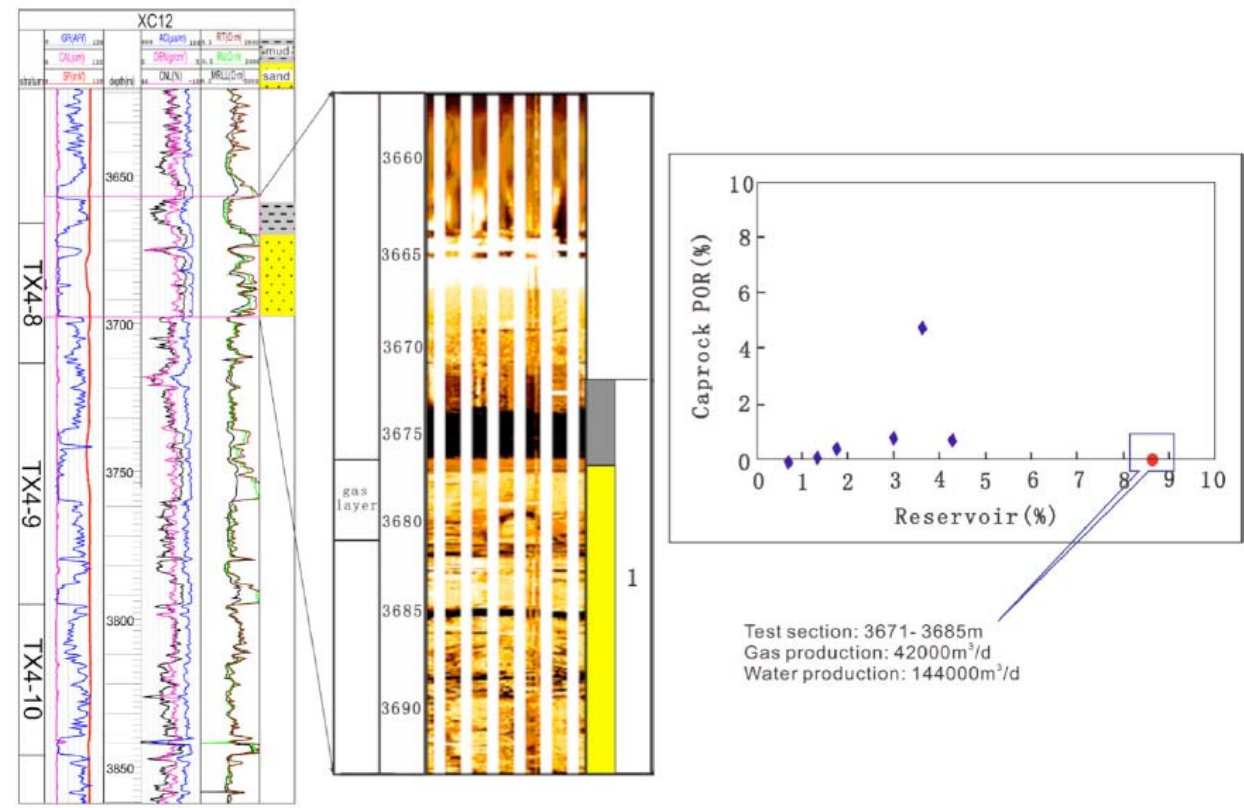

Fig. (1). Dual porosity scatter diagram of high production layers, Well XC12.

Table 2. Major reservoir and caprock parameters of low production layers, Well XC12.

\begin{tabular}{|c|c|c|c|c|c|c|}
\hline & \multicolumn{3}{|c|}{ Caprock sample } & \multicolumn{3}{|c|}{ Reservoir sample } \\
\hline & 1 & 2 & 3 & 1 & 2 & 3 \\
\hline Top depth (m) & 3724 & 3738 & 3758 & 3735 & 3743.7 & 3776.5 \\
\hline Bottom depth (m) & 3735 & 3743.7 & 3776.5 & 3738 & 3758 & 3778.5 \\
\hline Thickness (m) & 11 & 5.7 & 18.5 & 3 & 14.3 & 2 \\
\hline POR (\%) & 0.785 & 4.676 & 0.738 & 3.005 & 3.636 & 4.3 \\
\hline PERM (mD) & 0.11 & 0.268 & 0.108 & 0.1 & 0.351 & 0.486 \\
\hline
\end{tabular}
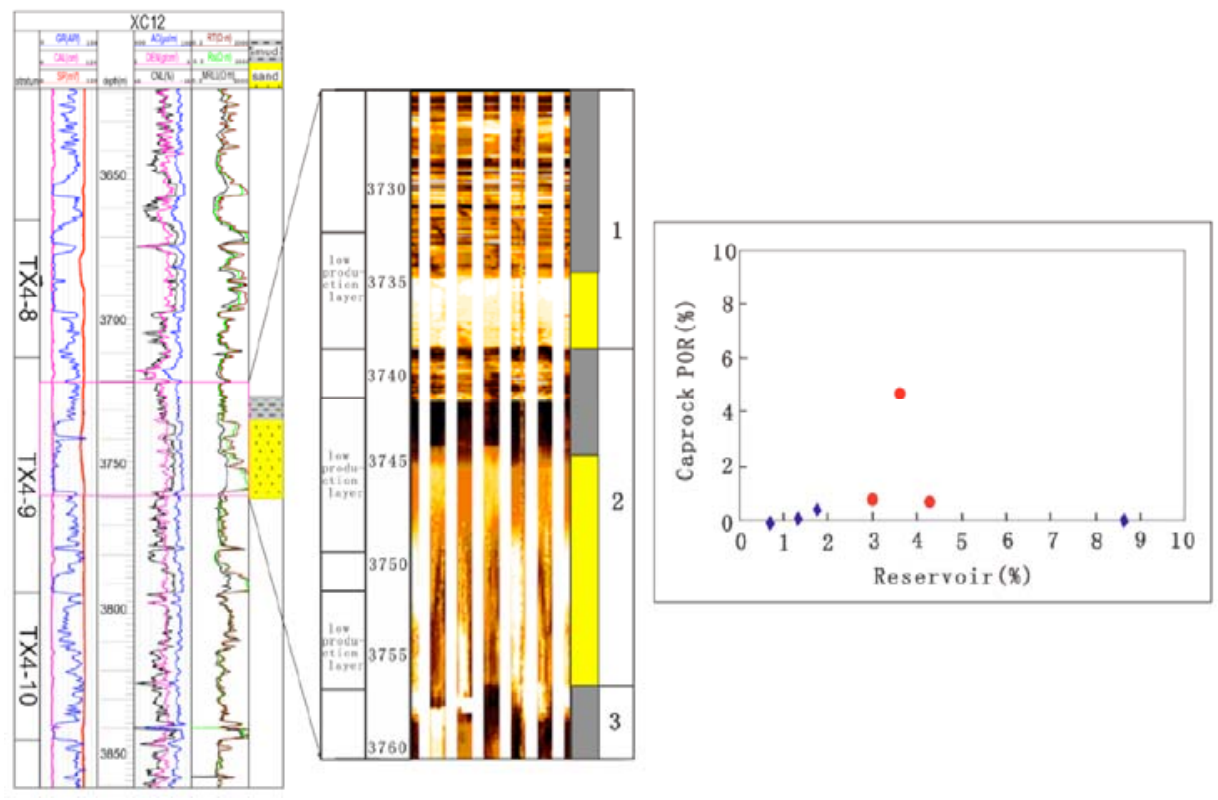

Fig. (2). Dual porosity scatter diagram of low production layers, Well XC12. 
Table 3. Major reservoir and caprock parameters of dry layers, Well XC12.

\begin{tabular}{|c|c|c|c|c|}
\hline Parameters & \multicolumn{2}{|c|}{ Caprock samples } & \multicolumn{2}{|c|}{ Reservoir samples } \\
\hline Bottom depth (m) & 3647 & 3665 & 3656.5 & 3672 \\
\hline Thickness (m) & 6 & 8.5 & 9.5 & 7 \\
\hline PERM (mD) & 0.01 & 0.012 & 0.068 & 0.1 \\
\hline
\end{tabular}

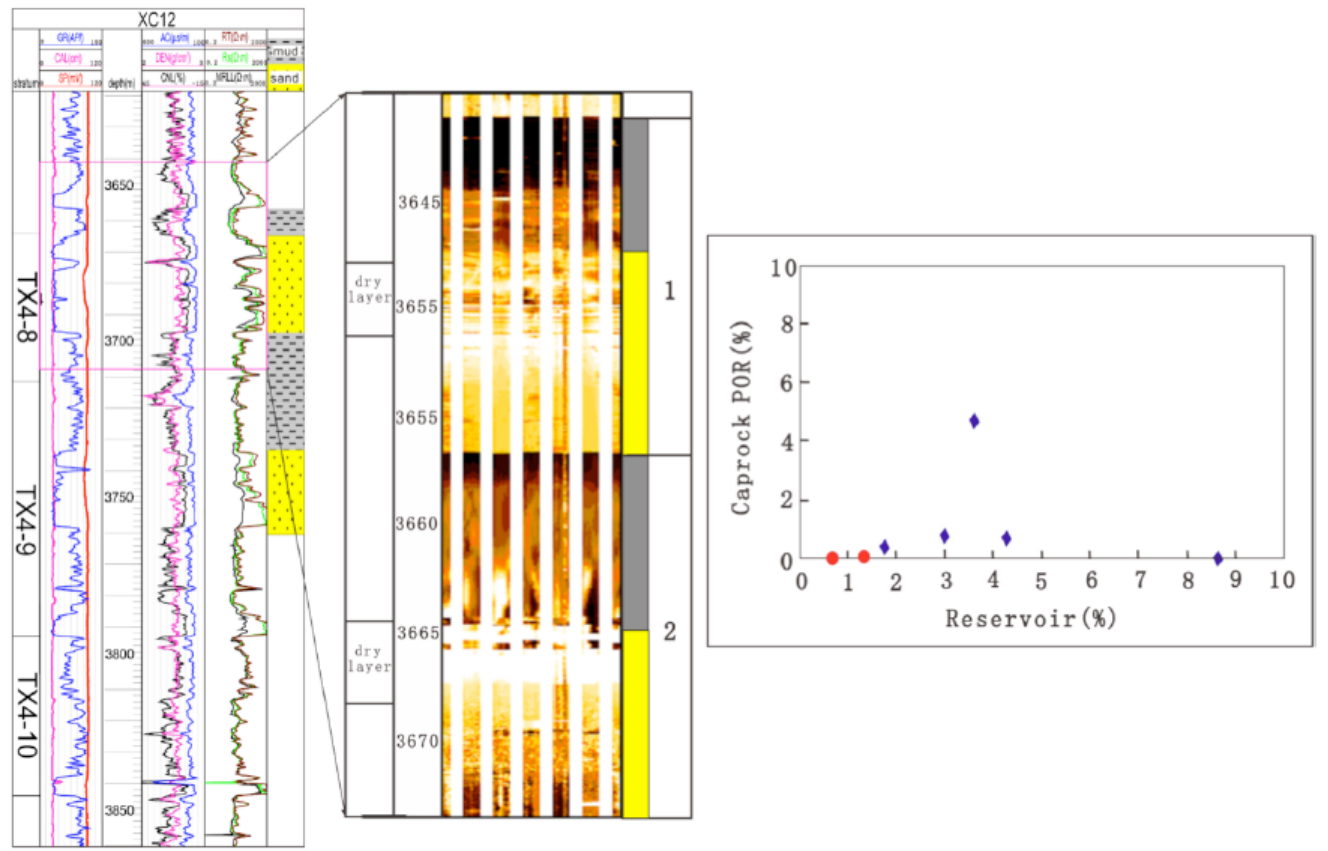

Fig. (3). Dual porosity scatter diagram of dry layers, Well XC12.

acquire the assemblage of the dual parameter, of which the reservoir porosity is smaller than $1.5 \%$ and the caprock porosity is smaller than $0.1 \%$, corresponding to the left-down part of the chart.

\section{CRITERION OF RESERVOIR-CAPROCK DUAL PARAMETER METHOD TO STUDY THE RESER- VOIR-CAPROCK ASSEMBLAGE OF DIFFERENT PRODUCTION LAYERS}

After discussing the reservoir-caprock assemblage of high production gas layer, low production gas layer and dry layer by reservoir-caprock dual parameter method, respectively, we count the reservoir porosity and caprock porosity of the assemblage in all the testing sections of commercial gas wells, Lian116, XC12, XC28 and X10, which is shown in the Table 4.

Based on the comprehensive comparison of the response characteristics of reservoir-caprock dual parameter from different testing sections in each well, the discrimination standard for the method to study reservoir-caprock assemblage of different gas layers is established as follows:
(1) For the high production gas layer, reservoir porosity is larger than $5 \%$ and caprock porosity is smaller than $2 \%$, inferring the high production gas layer corresponds to a high reservoir porosity and a low caprock porosity.

(2) For the low production gas layer, reservoir porosity is between $3 \%$ and $5 \%$ and caprock porosity lies between $0.5 \%$ and $5 \%$, that is the low production gas layer develops a low reservoir porosity and caprock porosity with a range distribution.

(3) For the dry layer, reservoir porosity and caprock porosity are smaller than $4 \%$ and $2.5 \%$, respectively, which means the dry layer is featured with low reservoir porosity and low caprock porosity despite the existence of some abnormal high values.

According to the reservoir-caprock assemblage characteristics shown in the Fig. (4) that is acquired through the reservoir porosity and caprock porosity, conclusions are drawn as follows:

(1) Assemblage with reservoir porosity larger than $5 \%$ and caprock porosity smaller than $2 \%$ is defined as favorable 
Table 4. Reservoir-caprock porosity of different production layers.

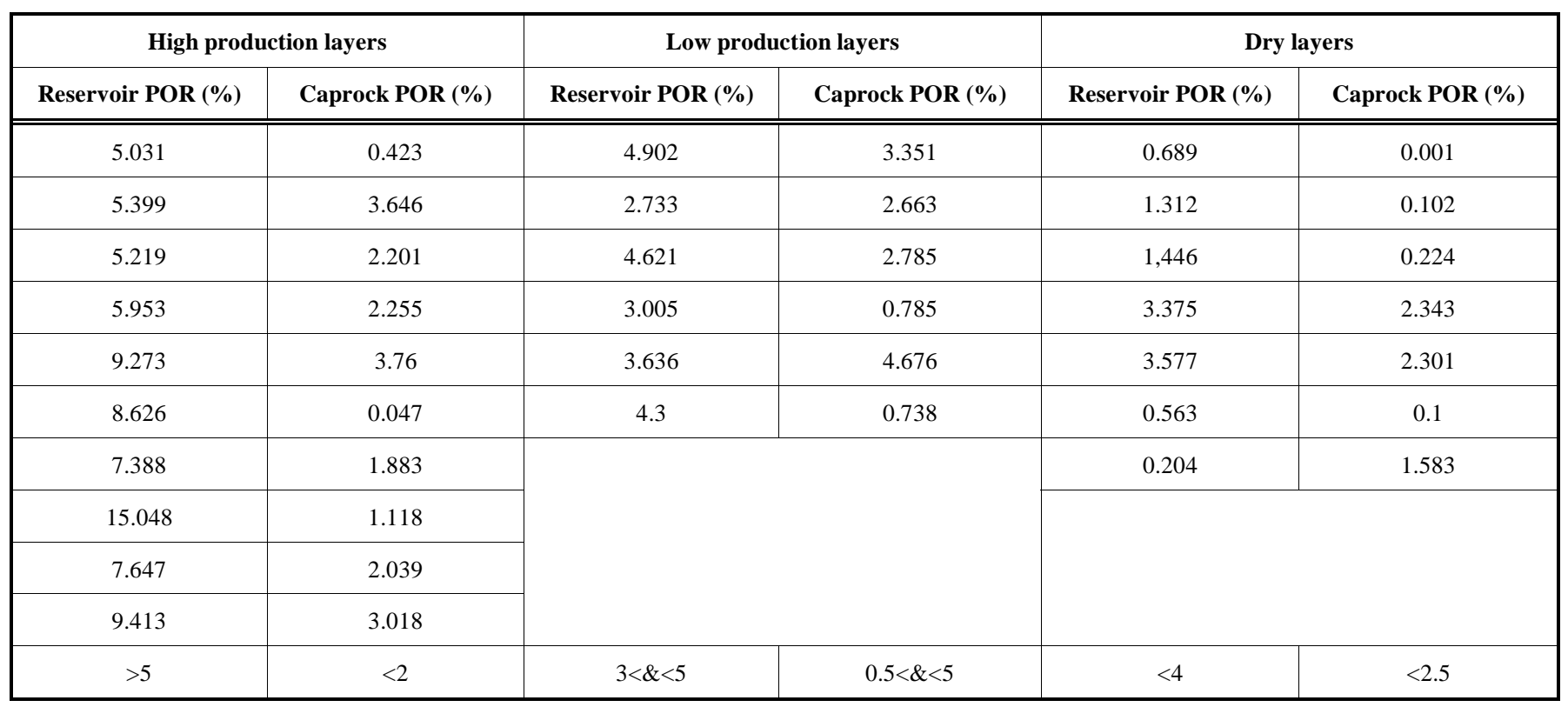

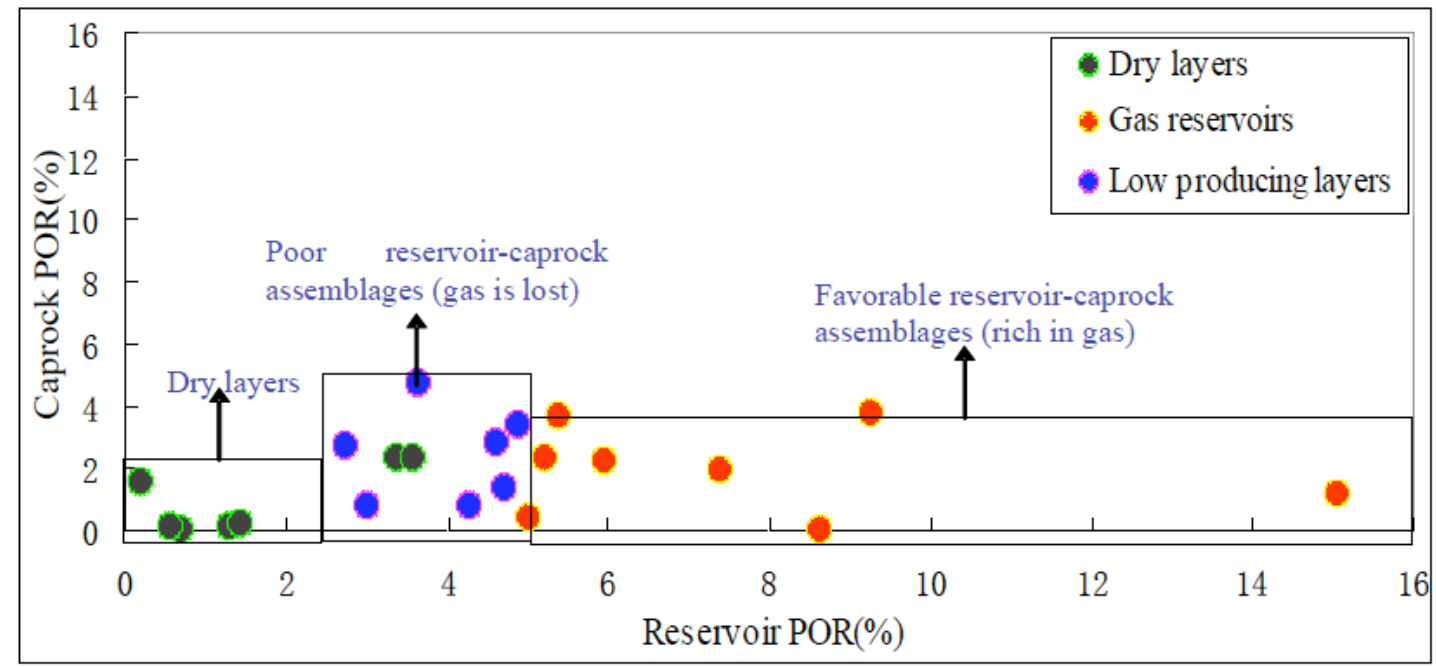

Fig. (4). Reservoir-caprock assemblage distribution of different producing layers by dual parameter method.

reservoir-caprock assemblage, usually corresponding to high production gas layer, whose dual parameters distributes in the favorable assemblage zone or the rightdown part of the distribution chart.

(2) Assemblage of which reservoir porosity is between $3 \%$ and $5 \%$ and caprock porosity is between a wide range of $0.5 \%$ and $5 \%$ is regarded as gas layer reservoir-caprock assemblage of low production, and the dual parameter lies in the middle part of the scatter diagram or the low production and poor assemblage zone of Fig. (4).

(3) Assemblage characterized with reservoir porosity smaller than $4 \%$ and overall caprock porosity smaller than $2.5 \%$ with some abnormal high values is interpreted to be dry layer reservoir-caprock assemblage, whose dual parameter is located in the right-left part of the scatter diagram or of the dry layer reservoir-caprock assemblage zone in Fig. (4).

\section{CONCLUSION}

(1) Reservoir-caprock dual parameter (reservoir porosity and caprock porosity) method is put forward to study the reservoir-caprock assemblage, and the principle for this method to discriminate the allocation relation of different producing layer as the high production, low production and dry layer is also clarified.

(2) Discrimination criterion for dual parameter method to identify different productivity reservoir-caprock assemblage has been established: $\ominus$ for high production gas layer, porosity is larger than $5 \%$ in reservoir and smaller than $2 \%$ in caprock. $\ominus$ for low production gas layer, porosity is $3 \% \sim 5 \%$ in reservoir and $0.5 \% \sim 5 \%$ in caprock. $\circledast$ for dry layer, porosity is smaller than $4 \%$ in reservoir and smaller than $2.5 \%$ in caprock. 


\section{CONFLICT OF INTEREST}

The authors confirm that this article content has no conflict of interest.

\section{ACKNOWLEDGEMENTS}

This study was financially supported by the Ministry of Land and Resources special funds for scientific research on public cause (Grant No. 201311107), the National Natural Science Foundation of China (Grant No. 41302107), the Fundamental Research Funds for the Central Universities (Grant No. 2652015222), the CNPC Innovation Foundation (Grant No. 2012D-5006-0103).

\section{REFERENCES}

[1] C. Q. Tan, Q. H. Lei, Z. Q. Song, “Application of well logging technology to interpretation and study of reservoir and covering strata combination", Geophysical Prospecting For Petroleum, vol. 38, no. 4, pp. 57-65, 1999.

[2] Y. P. Shi, "Image logging geological interpretation system", $X i$ 'an University of Science and Technology, Xi' an, China, 2008.

[3] G. P. Li, Q. Shi, S. Y. Wang, "A study of reservoir-cap rock log interpretation method", Well Logging Technology, vol. 21, no. 2, pp. 98-104, 1997.

[4] Q. Shi, "Combination of fractured reservoir and cap rock and accumulation relationship of oil and gas in Yinan area", Well Logging Technology, vol. 26, no. 4, pp. 302-305, 2002.
[5] G. P. Li, H. Z. Xu, "Identify the shale pseudo cap from log information”, Geological Well Logging, vol. 15, no. 4, pp. 230-239, 1991.

[6] X. S. Lu, Y. L. Jiang, Y. Song, "Influence of mechanical properties and stress state of caprock on its sealing performance: taking Kela2 gas field as an example", Natural Gas Industry, vol. 27, no. 8, pp. 48-51, 2007.

[7] G. Fu, "Seal evolution characteristics of over pressured mudstone and its seal efficiency", Journal of Daqing Petroleum Institute, vol. 31, no. 5, pp. 7-9, 2007.

[8] Y. F. Lv, J. Wan, Z. X. Sha, X. F. Fu, G. Fu, "Evaluation method for seal ability of caprock destructed by faulting and its application", Chinese Journal of Geology (Scientia Geologica Sinica), vol. 43, no. 1, pp.162-174, 2008.

[9] M. L. Sun, G. D. Liu, J. Li, "Features of caprocks of gas pools and criteria of identification", Natural Gas Industry, vol. 28, no. 8, pp.36-38, 2008.

[10] D. J. Yang, "Effect of overpressure on mudstone caprock sealing gas in each phase", Petroleum Geology \& Oilfield Development in Daqing, vol. 27, no. 2, pp. 12-15, 2008.

[11] S. G. Wu, X. L. Wang, Y. X. Ji, Y. Z. Liu, W. G. Han, “Application of forecasting structural cracks technique of 3D Move in Chengdao buried hill", Science in China (Series D:Earth Sciences), vol. 4, no. 9, pp. 1403-1410, 2005.

[12] Anirbid Sircar, "Hydrocarbon production from fractured basement formations", Current Science, vol. 87, no. 2, pp. 147-151, 2004.

[13] C. H. Jiao, Y. F. Gu, "Application of logging data in evaluating caprocks", Well Logging Technology, vol. 28, no. 1, pp. 45-47, 2004.

[14] X. B.Yang, Z. P. Liu, Q. L.Wang, "Identification application to pseudo reservoir in Xiagou interval of Qingxi field with electrical images”, Petroleum Instruments, vol. 20, no. 5, pp. 50-52, 2006.

(C) Xu et al.; Licensee Bentham Open.

This is an open access article licensed under the terms of the Creative Commons Attribution Non-Commercial License (http://creativecommons.org/licenses/by-nc/3.0/) which permits unrestricted, non-commercial use, distribution and reproduction in any medium, provided the work is properly cited. 